\title{
16
}

\section{CASMAC - A Co-operative Approach to University Administrative Computing}

\author{
Helene Dimmitt \\ La Trobe University, Victoria, 3083, Australia
}

\begin{abstract}
CASMAC, or Core Australian Specification for Management and Administrative Computing, is a project of Australian universities to develop first a specification and then integrated functional systems to meet $80 \%$ of administration computing needs in the major areas of finance, human resources, physical resources, research and consultancy, student records and executive reporting. The paper gives an account of the project to date and comments on the issues arising from such a co-operative venture in software development.
\end{abstract}

\section{INTRODUCTION}

There is currently under way in Australia a consortium approach to the development of university administration computer systems, which is proving an interesting experience for the universities and the commercial software houses involved. The issues arising in project management are testing both sides, as it is a rare occurrence for the universities to contract for software development, most systems being written in-house or bought as a package.

Keyword Codes: K.6.1, K.3.1, J.1

Keywords: Management of Information Systems; Project and People

Management; Computer Uses in Education; Administrative Data Processing

\section{THE CASMAC SPECIFICATION}

In 1990 the Australian Vice-Chancellors' Committee (AVCC) which is the cooperative forum of the heads of the 36 Australian universities, undertook a project to create a common specification for the core administrative computing systems required by universities. The project and the specification are known as CASMAC, Core Australian Specification for Management and Administrative Computing.

The project is a response to the perceived waste of resources involved in each university in Australia developing its own set of administrative systems, when there is a great deal in common across the institutions. It is also true that there are some differences between institutions, and so the aim was stated conservatively, to produce a specification for the core $80 \%$ of each application. The Commonwealth Government also has an interest in university administrative systems, as these are the source of the ever-increasing quantities of statistics and records that the Department of Employment, Education and Training require from 
institutions. There had been some friction between DEET and institutions over the workload involved in meeting the DEET requirements, in particular the changes to the data collection that occur virtually every year at short notice. On occasions, some institutions declared themselves unable to meet the DEET requirements because it was too difficult or costly to modify their computer systems in the time given.

The Government publishes a data dictionary of its requirements, and it agreed to provide some funding for the CASMAC specification provided that its data needs were incorporated.

The notion of CASMAC is based on an initiative in the United Kingdom by the University Grants Committee in response to concern about the quality of data provided to it by universities. The first step of the Australian project was to examine the UK specification, referred to as the "MAC blueprint", and to use it as the starting point for the Australian specification.

The CASMAC was drawn up by working groups of expert staff drawn from Australian universities, under the control of an AVCC Steering Committee. CASMAC version 2.0 was provided to universities in late 1991, and as a result of feedback from them, was reissued as version 2.1 in November 1992.

The specification covers the five major applications of

Finance

Human Resources

Physical Resources

Research and Consultancy

Student Records

The specification consists of data flow diagrams, data model diagrams and a data dictionary. It also specifies the requirement for an Executive Reporting function which will enable the combination of data from all five applications.

The AVCC not only adopted the CASMAC version 2.1 as a specification that all Australian universities could be expected to meet (over time) but also undertook to maintain the specification, in particular updating it regularly for changed government requirements. In this respect, the Australian project has gone beyond the UK one, where the MAC blueprint has been only a starting point.

The first major revision of the CASMAC is about to commence, to incorporate all the agreed amendments and additions identified through the experience of the Universities in embarking on the implementation of systems based on the CASMAC.

\section{THE DEVELOPMENT FAMILIES}

Building on the achievement of the CASMAC specification, the Australian ViceChancellors agreed to take the next step and invite commercial software providers to tender for development of the applications in conjunction with groups of universities.

A number of factors were suggested on which universities might group themselves, including location or type of institution, but the software environment proved to be the deciding factor. In the light of the tenders, and given the number of institutions involved, two "families" were established, UniPower, based on Powerhouse software and UniOn, based on Oracle. In both cases the commercial software houses had been involved in the UK MAC system developments.

Each family has been set up as a company, operating under a contract with the commercial supplier. There are 19 universities in the UniPower family and 11 in the UniOn, with a few universities preferring to stay with their own systems. 


\section{EXPECTED BENEFITS}

A major factor in universities choosing to join a family is that the cost to receive all five applications is less than half the kind of costs institutions have been incurring through in-house development. Part of this cost saving is the economy of scale, helped by the substantial contribution the government is making. This was conditional on a very large number of institutions joining the development project, and led to a certain peer-group pressure to join.

In addition to the development cost saving, there is also the expected saving in a consortium approach to modifications in the future, in particular the need for regular changes to meet the government's demands. These relate not only to statistical reporting, but increasingly to operational matters including the collection of a charge for university education, which can be deferred as a future taxation liability.

The advantage of having an integrated set of systems, enabling easy executive reporting, is the other major benefit for universities. With the existing in-house development, there is a cycle of sequential application replacement over such a period of years as to ensure that technology has moved on a good deal between the oldest system and the latest, so that assembling data from multiple systems is extremely difficult.

Unlike the UK situation, most institutions in Australia have at least two or three of the application systems being offered in CASMAC already developed to a relatively high degree of functional and technological sophistication. Physical Resources systems are the least widespread. However, most institutions feel they will be sacrificing at least one better inhouse application system for the benefit of taking the full CASMAC set of applications.

While there were a core group of institutions already using Powerhouse and Oracle software, many institutions are abandoning other software bases to join one of these two families. Each of the successful software houses has had to undertake to make their systems operational over a range of hardware platforms and operating systems.

\section{EXPERIENCE TO DATE}

The author's university is a member of the UniPower consortium and the following points relate to that experience.

The first phase has been to develop the Initial Specification for each of the five applications, expanding the CASMAC specification, and the last of these is almost complete, with the earliest now well into the Detailed Design phase.

A team consisting of a few user experts from among the universities, one information technology professional from the universities and one from the commercial company, has been set up for each application. There are also teams for Executive Reporting, Quality Assurance and Standards, Integration and Testing, and Implementation, Training and Documentation.

\subsection{People problems}

For each application, a university has undertaken to be the lead site, providing the chairman and secretarial support, a location for meetings and facilities for testing. For one application, the university who undertook the lead site role subsequently found itself unable to continue just as the intensive Initial Specification phase was about to start, and the author's university was pressured to accept this responsibility. Now the staff member who was chairman has resigned from the university only a few weeks into the project, but it is expected that a satisfactory substitute can be found. Other teams have remained stable to date. 
The commercial company has had difficulty recruiting information technology staff of appropriate calibre who have some knowledge of the applications, especially those of Student Records and Research and Consultancy which are unique to tertiary education institutions. They have been forced to use one person to cover two applications, requiring some slippage in the schedule.

\subsection{Size of project}

The commercial company has further needed to extend the schedule because of its misestimation of the amount of work involved in the project. The delivery date for the last of the applications on the base hardware/operating system is now September 1995, compared with April 1995 in the initial contract.

The company has based its bid for the contract on being able to use its British MAC products as the basis for most of the Australian ones. Having seen the full Initial Specification for the Student Records system, it has realised that the Australian requirements are more different than it had understood. The need to write this application from scratch has caused further slippage in the schedule.

Other applications are also proving larger than the company envisaged. The contract requires that any additions to the applications (requirements not mentioned in the CASMAC) are to be paid for above the contract price, and a few such variances have been identified. Most notable is the omission of an assets register from the CASMAC, perhaps because finance staff assumed it was in the Physical Resources application, and vice-versa.

However, the commercial company has been identifying an extraordinary number of variances (134 at one stage in the Students Records application) and this reflects the gap in understanding between the universities and the company in the interpretation of the

CASMAC. Universities are having to learn to give way on particular functionality that is not of interest to the whole group, but to a greater extent the company is having to expand its ideas of the requirements.

The UniOn family believed from the outset that its commercial company, which also tendered on the basis of MAC products, had under-estimated the differences and would do better to incorporate some third-party products already in use in Australia. They have completed their initial specification phase using their own resources and prior to contracting with their company in the hope of avoiding the problems the UniPower group has run into.

\subsection{Definition of core systems}

It has been clear from the outset that a definition of a core specification covering $80 \%$ of an institution's requirements was dangerously vague. As Powerhouse provides powerful reporting tools, the universities can readily add their own reports, or modify those provided in the core. Some initial thinking was that very few reports would be provided, and this would constitute the $20 \%$ institutions provided for themselves, but many reports are in fact included in the Initial Specifications.

The Executive Reporting "application" has always been vague, referring primarily to the availability of software reporting tools, and the team is still struggling to identify whether any actual reports will be provided under this heading, and whether an extract database for executive reporting will be provided. Many institutions see this latter as a necessity as they do not have the hardware resources to support free interrogation of the full integrated database.

To achieve the advantage of receiving timely modifications from the company after implementation in response for instance to government requirements, it will be essential that any additions of individual institutions to the core systems be in the form of separate subsystems. Institutions cannot afford to insist on local customisations affecting the structure of 
the database. While this point is understood in the author's institution by the administrators as well as the information technology staff, there is expected to be some difficulty in persuading academic staff that the sacrifice of some complexities in course and subject structures, for instance, is worthwhile to facilitate the institution's response to government demands.

\subsection{Design issues}

The aim of implementing the CASMAC specification is to achieve a fully integrated set of application systems. The first requirement is a fully integrated database and to achieve this, a Base System is being designed.

It has been proposed to have a single person table, to provide basic data on each person known to the system, be they student, staff, debtor or hirer of facilities. This raised the question of who would maintain the data, as university administrations are divided into separate divisions of student administration, personnel, finance and physical resources, each accustomed to maintaining their own records.

This design has been agreed to be too radical to fit into current organisations, and there is instead to be a person master index, to link different records with different id numbers relating to the same person across applications.

The design still includes a single organisation structure table with common organisational unit numbers and names (faculties, schools, departments). A maximum of seven leveis of organisational hierarchy is being allowed. This common organisational unit coding is important in providing standardised data to the Government and being able to draw data together across different applications for internal management information.

The university technical staff involved in the project have been critical of the commercial company's lack of sophistication in use of a relational database management system. This came to the surface in a dispute over the use of "triggers" to perform an action when the database is changed. This is seen by the university staff as a secure and efficient way to achieve an audit trail, rather than including such code in each application program. Such issues reflect the fairly advanced technical state of administration computing in at least some universities in Australia, and have clearly not coincided with the expectations of the commercial company.

On the application side, the sophistication of the systems expected has also been beyond the assumptions of the commercial company. The notion of systems relatively free of paper is accepted in at least some institutions, leading to a demand for all applications to maintain the history of values in key tables. This went without saying on the user side, and has led to arguments over whether this constituted a variance to the CASMAC in each application.

\subsection{Training}

A matter of considerable debate at this stage is the provision of training, in the Powerhouse products and in the applications when available. Universities being in the business of teaching, and that largely free of charge, there has been an adverse reaction to the charges proposed to the consortium, in particular by the software supplier, and a belief that the consortium could provide its own training more effectively. Some universities favour a train-the-trainer approach, where a few key people will receive commercial training and then pass it on within the institution. One or two universities see themselves as substituting for the supplier to sell training to their fellow institutions, at a lower rate. 


\section{CONCLUSION}

No doubt there will be many further issues that emerge from this project, which represents an unusual attempt for universities to co-operate with each other and a commercial company to achieve a major project in the use of information technology in educational management. To date it has been a learning experience, not least for the commercial company. 